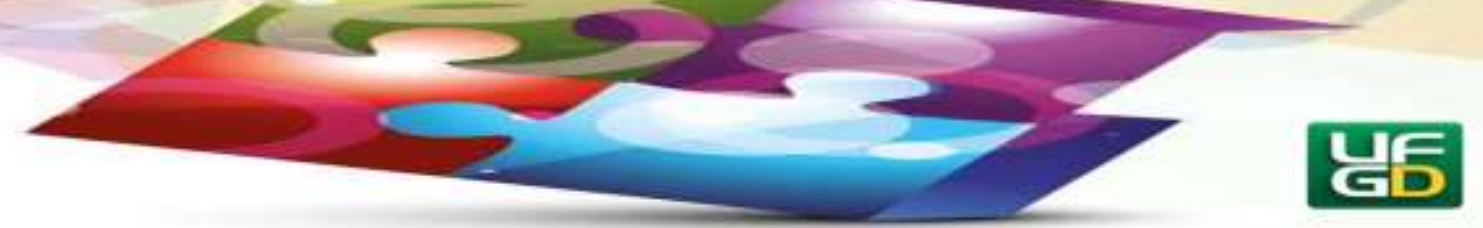

\title{
A BASE NACIONAL COMUM CURRICULAR E SUAS IMPLICAÇÕES NA PROPOSTA CURRICULAR DE CIÊNCIAS NATURAIS DO ESTADO DO ACRE
}

\author{
THE COMMON CURRICULAR NATIONAL BASE AND ITS IMPLICATIONS IN THE
}

CURRICULAR PROPOSAL FOR NATURAL SCIENCES IN THE STATE OF ACRE

Adriana Ramos dos SANTOS ${ }^{1}$

Letícia Mendonça Lopes RIBEIRO²

\begin{abstract}
Resumo
Desde a homologação da Base Nacional Comum Curricular, em 2017, as redes e sistemas de ensino têm se mobilizado na (re) elaboração de seus currículos para levar esse documento para as salas de aula. Assim, considerando a trajetória de cada estado, o presente artigo tem por objetivo tecer algumas considerações sobre a BNCC e suas implicações no processo de (re) formulação da Proposta Curricular de Ciências Naturais do estado do Acre, buscando discutir as divergências, os limites e possibilidades que a definição de uma BNCC apresenta para o ensino de Ciências , com vistas a contribuir com o debate em curso. Metodologicamente esse estudo caracteriza-se como uma pesquisa qualitativa e utiliza a combinação das pesquisas bibliográfica e documental para dar destaque ao ensino de Ciências na BNCC - $3^{\text {a }}$ versão (BRASIL, 2017) e nos atuais cadernos de Orientação Curricular do estado do Acre (2009, 2010). As reflexões construídas ao longo da investigação revelaram que o Referencial Curricular do Acre foi (re)elaborado com a finalidade de se alinhar a BNCC, mas incorpora na sua estrutura itens que se propõem a favorecer uma compreensão mais precisa do que é pretendido; e na definição de conteúdo acrescenta aqueles que aprofundam a identidade acreana, buscando, assim, promover o conhecimento de aspectos importantes para a cultura e a história do Estado, ou seja, busca aprimorar o currículo, cuidando para que as características culturais, socioambientais e econômicas da sociedade acreana estejam contempladas.
\end{abstract}

Palavras-chave: BNCC. Ensino de Ciências. Orientação Curricular do Acre.

\begin{abstract}
Since the approval of the BNCC, in 2017, educational organizations and teaching systems have mobilized to re-elaborate and promote the curriculum document for the classrooms. Thus, considering the trajectory of each state, this paper aims to present considerations about the BNCC and its implications in the process of reformulating the Curricular Proposal for the Natural Sciences content in the state of Acre, Brazil, when seeking to discuss the divergences, limits and possibilities that the definition of a base document represents for science teaching. The methodology of this study is characterized as a qualitative research and uses the combination of bibliographic and documentary research to highlight Science teaching at BNCC in its third version (BRASIL, 2017) and in the current curricular guidance books of the state of

\footnotetext{
1 Doutora em Educação, Professora do Centro de Educação, Letras e Artes da Universidade Federal do Acre. E-mail: adrianaramos.ufac@gmail.com.

${ }^{2}$ Mestranda em Educação (PUC/MG) E-mail: leticiamendonca@yahoo.com.br
} 


\section{HORIZONTES - REVISTA DE EDUCACATO}

e-ISSN: $2318-1540$

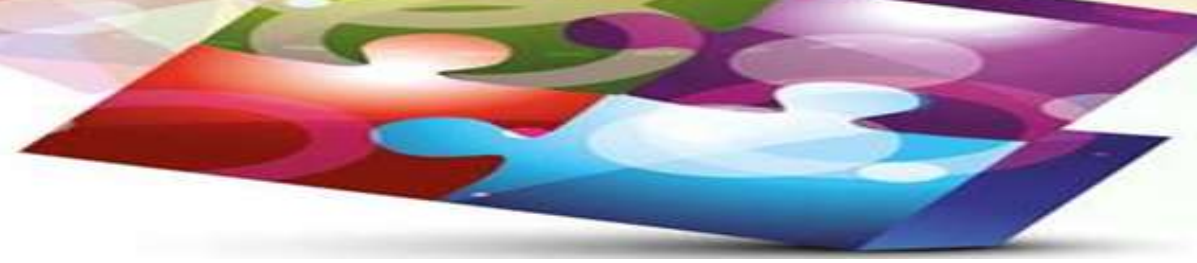

Acre $(2009,2010)$. The reflections built during the investigation revealed that the Acre's Curriculum Reference was reworked in order to align with the BNCC, but incorporated in its structure items that aim to favor a more precise understanding of what is intended; deepening the Acre identity in its contents and seeking to promote knowledge of important aspects for the culture and history of the State. So, it seeks to improve the curriculum, taking care that the cultural, socio-environmental and economic characteristics of the Acre society are covered.

Key words: BNCC. Science teaching. Curriculum Guidelines of Acre.

\section{INTRODUÇÃO}

O documento de referência da Base Nacional Comum Curricular (BNCC), foi homologado em 2017, apresentado a partir de sua terceira versão. Por se apresentar como um documento, que servirá de base para a construção dos currículos das escolas públicas e privadas de Educação Básica, sua publicação e uso estão gerando debates e configurando novos desafios para a educação, tanto em seus aspectos legais quanto em seus aspectos teórico-metodológicos e ideológicos. Logo, o caráter normativo da BNCC, que torna obrigatória a (re)elaboração dos currículos das redes de ensino, estabelece direitos e objetivos de aprendizagens comuns para todo país.

Assim, considerando a trajetória de cada estado, o presente artigo tem por objetivo tecer algumas considerações sobre a BNCC e suas implicações no processo de (re)formulação da Proposta Curricular de Ciências Naturais do estado do Acre, buscando discutir as divergências, os limites e possibilidades que a definição de uma BNCC apresenta para a área, com vistas a contribuir com o debate em curso.

Nessa perspectiva, ressaltamos que o trabalho está organizado em três seções. A primeira apresenta um breve histórico de sua formulação e algumas das propostas intrínsecas à sua implantação; a segunda seção discute o contexto de formulação da BNCC em relação à ao ensino de Ciências e, já na terceira seção, realiza-se algumas análises reflexivas sobre a BNCC e o processo de reformulação da Proposta Curricular de Ciências do Estado do Acre, destacando as divergências, os limites e as possibilidades entre os documentos. Essas reflexões, entretanto, não pretendem ser indicativas de finalizar os muitos diálogos que essa proposta incita. Ao contrário: a discussão, ora apresentada, objetiva socializar novos elementos para subsidiar os debates em pauta.

\section{A BNCC E SEU CONVITE A REPENSAR A EDUCAÇÃO PARA A CIDADANIA}




\section{HORIZONTES - REVISTA DE EDUCAÇÃO}

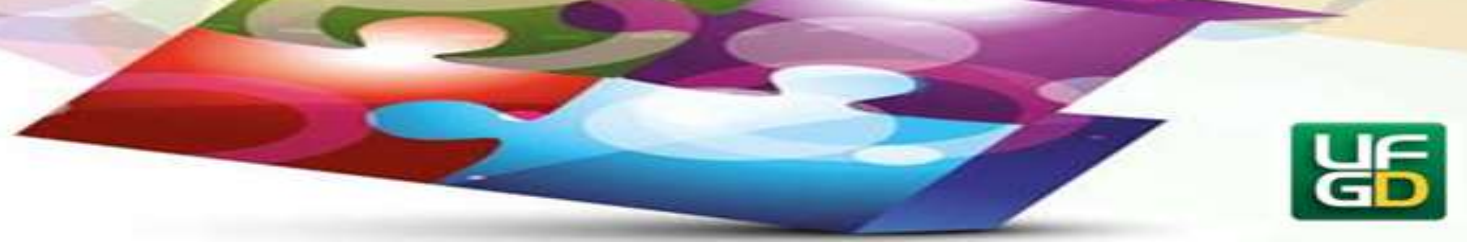

Apesar das primeiras discussões sobre a BNCC datarem de 2012, as reflexões sobre a sua a necessidade, na Educação Básica brasileira, não é recente. De acordo com Macedo (2015), a prerrogativa de uma base curricular teria se iniciado com a Constituição Federal de 1988, seguindo com a publicação da Lei de Diretrizes e Bases da Educação Nacional (LDBEN) de 1996, a elaboração dos Parâmetros Curriculares Nacionais (PCN) em 1998 e, então, culminando com a promulgação das Diretrizes Curriculares Nacionais Gerais para a Educação Básica e do Plano Nacional de Educação (PNE), já em 2010. Entretanto, Macedo (2015, p. 892) ressalta que, ao vislumbrar bases curriculares comuns, todos estes documentos "se configuravam em diretrizes para a educação e não numa proposta curricular ou listagem de conteúdos".

Ao se pensar na BNCC e sua essencialidade na apresentação de conteúdos escolares, análises e julgamentos surgiram e se fortaleceram no meio acadêmico, desde a sua construção até os dias atuais, com a sua publicação. Entre inúmeras razões, Lopes (2018, p. 23) critica o documento por perceber, no cerne da BNCC, "a insistência em um vínculo imediato entre educação e desenvolvimento econômico" e "a valorização do caráter salvacionista da educação". A autora destaca que, neste chamado caráter salvacionista, a educação ganha a responsabilidade de resolver quase todos os problemas sociais - algo absolutamente utópico.

Assim sendo, afirma-se a necessidade de manter em mente a ideia de educação para cidadania, tão presente no texto constitucional e na LDBEN. Quanto à BNCC, de acordo com Macedo (2015) - em sua análise do texto preliminar, de 2014 - as propostas de educação para a cidadania inclusiva não são perpetuadas. Na verdade, "talvez se possa dizer, apenas, que os direitos elencados tornaram-se mais explicitamente individuais" (MACEDO, 2015, p. 897), algo que se afasta da prerrogativa coletiva na qual se concentra a cidadania.

Logo, é importante ressaltar a caracterização do que se entende por cidadania. De acordo com Cury, Reis e Zanardi (2018, p. 19), a cidadania é "a capacidade de participar autonomamente dos destinos de uma comunidade, alargando o raio dessa participação, podendo um governado também o de ser governante". Nesse sentido, é fundamental associar esta ideia de cidadania à educação como direito, principalmente na Educação Básica. Para Cury (2008, p. 294), a Educação Básica como direito "significa um recorte universalista próprio de uma cidadania ampliada e ansiosa por encontros e reencontros com a democracia civil, social, política e cultural". É nesta perspectiva que o currículo se associa a uma perspectiva cidadã. Na 


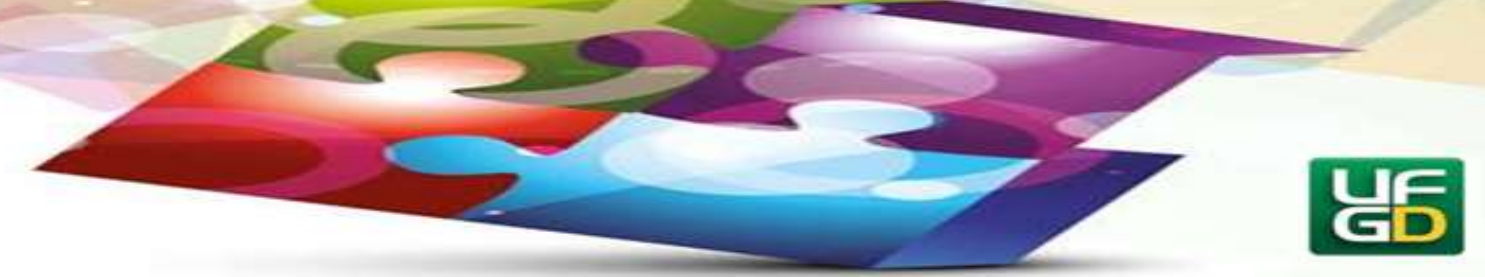

verdade, "pode-se dizer que um currículo nacional se cruza como uma função social do Estado, que é o de atender a um direito do cidadão que busca na educação escolar uma via de cidadania compartilhada com seus concidadãos” (CURY, REIS, ZANARDI, 2018, p. 20).

Entretanto, é fundamental observar que, mesmo estabelecendo um vínculo entre a BNCC e a cidadania, a implementação deste documento não garante uma educação cidadã. Ao contrário: é essencial reconhecermos "há muito mais conhecimentos no mundo do que aquilo que se pode ensinar nas escolas" e, portanto, "quando escolhemos o que entra nos currículos, escolhemos o que sai e esta decisão é política, favorece a alguns e prejudica outros" (OLIVEIRA, 2018, p. 57).

Por essa razão, precisamos pensar na efetividade da BNCC, especificamente para o ensino de Ciências, como uma oportunidade de exercer e fortalecer a cidadania escolar - e não como mais uma alternativa que reforça a desigualdade social, ao manter o simples status da educação como a grande responsável pelo desenvolvimento econômico. Essa é a busca que os educadores, no estado do Acre, cultivam diante da manutenção de uma escola democrática, que almeja uma melhoria da educação para a redução das desigualdades sociais entre todos os acreanos.

\section{A BNCC E O ENSINO DE CIÊNCIAS}

A BNCC propõe para o ensino de Ciências da Natureza no Ensino Fundamental, como um de seus princípios básicos, o desenvolvimento do Letramento Científico e que os estudantes desenvolvam habilidades, a partir de procedimentos investigativos, compreendendo a natureza da Ciência como produto de uma construção histórica, social, cultural e humana (BRASIL, 2017).

A estrutura conceitual da BNCC de Ciências da Natureza para o Ensino Fundamental está ancorada na proposição de uma educação em Ciência que proporcione ao educando o desenvolvimento do letramento científico, o que exige as competências para:

1. Explicar fenômenos cientificamente: reconhecer, oferecer e avaliar explicações para fenômenos naturais e tecnológicos;

2. Avaliar e planejar investigações científicas: descrever e avaliar investigações científicas e propor formas de abordar questões cientificamente; 


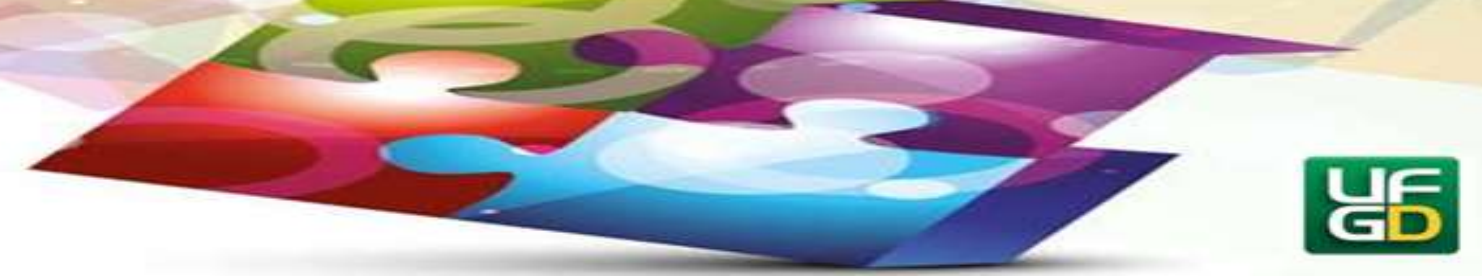

3. Interpretar dados e evidências cientificamente: analisar e avaliar os dados, afirmações e argumentos, tirando conclusões científicas apropriadas (BRASIL, 2017).

A discussão sobre o letramento científico na BNCC encontra suporte na percepção da necessidade emergente de formar os alunos para atuação na sociedade, largamente cercada por artefatos científicos e tecnológicos. Essa capacidade de compreensão e interpretação do mundo está diretamente relacionada com o desenvolvimento científico e tecnológico da sociedade atual e deve avaliar riscos e benefícios do uso das diferentes tecnologias (BRASIL, 2017).

Dessa forma, segundo a BNCC, espera-se que os estudantes tenham um novo olhar sobre o mundo que os cerca, como também façam escolhas e intervenções conscientes e pautadas nos princípios da sustentabilidade e do bem comum.

Nesta proposta de currículo, são indicados como conteúdos os conhecimentos científicos necessários para ampliar a compreensão de questões relacionadas ao meio ambiente, saúde, sexualidade, ética, pluralidade cultural, trabalho e consumo - como também os conteúdos que traduzam especificidade em nível local.

A BNCC orienta que, nos anos iniciais, seja valorizada a curiosidade natural das crianças. Esse deve ser o ponto de partida de atividades que assegurem a eles construir conhecimentos sistematizados de Ciências, oferecendo-lhes elementos para que compreendam desde fenômenos de seu ambiente imediato até temáticas mais amplas. (BRASIL, 2017, p.329). É importante, portanto, que o professor oportunize às crianças a vivência de situações e a realização de atividades para que observem, vivenciem e discutam os fenômenos naturais, assim como a prática dos registros, que favorece a formação de competência leitora e escritora por meio de propostas pedagógicas diversificadas, também representam uma importante metodologia para o processo de ensino aprendizagem.

É nesse sentido que, nos anos iniciais, orienta-se que as crianças ampliem os seus conhecimentos e apreço pelo seu corpo, identifiquem os cuidados necessários para a manutenção da saúde e integridade do organismo e desenvolvam atitudes de respeito e acolhimento pelas diferenças individuais, tanto no que diz respeito à diversidade étnico-cultural quanto em relação à inclusão de alunos da educação especial (BRASIL, 2017). 


\section{HORIZONTES - REVISTA DE EDUCACATO}

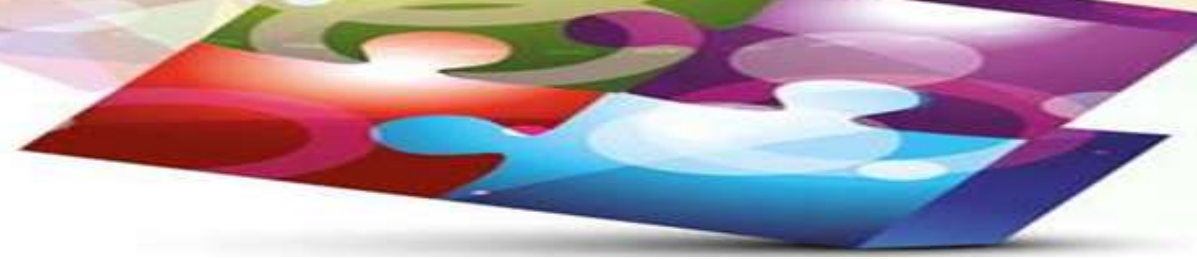

Já para os anos finais do ensino fundamental, a exploração dessas vivências, saberes, interesses e curiosidades dos alunos sobre o mundo natural e material, continuam sendo essências, entretanto sugere-se uma ampliação progressiva da capacidade de abstração e da autonomia de ação e de pensamento, e o aumento do interesse dos alunos pela vida social e pela busca de uma identidade própria.

Essas características possibilitam a eles, em sua formação científica, explorar aspectos mais complexos das relações consigo mesmos, com os outros, com a natureza, com as tecnologias e com o ambiente; ter consciência dos valores éticos e políticos envolvidos nessas relações; e, cada vez mais, atuar socialmente com respeito, responsabilidade, solidariedade, cooperação e repúdio à discriminação. (BRASIL, 2017, p. 341).

Os alunos nessa etapa do ensino fundamental devem ser capazes de estabelecer relações ainda mais profundas entre a ciência, a natureza, a tecnologia e a sociedade, o que significa lançar mão do conhecimento científico e tecnológico para compreender os fenômenos e conhecer o mundo, o ambiente, a dinâmica da natureza. Nessa perspectiva, é fundamental que tenham condições de ser protagonistas na escolha de posicionamentos que valorizem as experiências pessoais e coletivas, e representem o autocuidado com seu corpo e o respeito com o do outro, na perspectiva do cuidado integral à saúde física, mental, sexual e reprodutiva.

O Currículo de Ciências aparece nessa proposta retomando pontos já discutidos na proposta dos PCN - competências e habilidades, agora se dirigem em 12 direitos de aprendizagens. Nos PCN tem 3 grandes áreas e agora 4 grandes áreas na Base que se interrelacionam.

Os objetivos gerais da área de Ciências são amplos e apesar de serem coerentes com aquilo que se espera de um aluno alfabetizado cientificamente, parecem difíceis de serem alcançados com o ensino de Ciências, majoritariamente conteudista, na maioria das escolas. Esses objetivos da área merecem uma discussão mais focada, dado a centralidade que parecem assumir, restringindo-se em número, mas garantindo sua sinalização de forma efetiva ao longo da Educação Básica, destacando aqueles que deveriam receber, em cada etapa, maior atenção pelos professores.

Outro ponto a observar é a coerência entre os objetivos gerais da área, os objetivos da área no Ensino Fundamental, em alguns casos, os objetivos parecem os mesmos, apenas enunciados de outro modo. Em outros, são apresentados objetivos específicos por nível de 


\section{HORIZONTES - REVISTA DE EDUCAÇÃO}

e-ISSN: $2318-1540$

ensino. No essencial, nos parece que os objetivos poderiam ser os mesmos, apenas com ênfases diferentes.

Além disso, a quantidade de diferentes temáticas: Materiais, propriedades e transformações; Ambiente, recursos e responsabilidades; Terra - constituição e movimento; Vida - constituição e evolução; e Sentidos, percepções e interações, propostas para serem trabalhadas torna-se incompatível de ser ministrada em duas aulas por semana, pois o ensino de Ciências vem sendo sacrificado em detrimento das disciplinas de Português e Matemática.

Em toda a proposta, seria desejável que os conteúdos de Ciências da Natureza nas duas fases do Ensino Fundamental fossem apresentados separadamente, uma vez que atendem a fases de escolarização que se organizam de formas distintas.

O documento traz vários aspectos positivos como a distribuição, ao longo da Educação Básica, dos conhecimentos das diferentes áreas da Ciência, como a Física, a Química, a Biologia e outras. A formalização dos conhecimentos de Física e de Química, usualmente concentrados no $9^{\circ}$ ano dos livros didáticos, passa a ser distribuída ao longo de todo o Ensino Fundamental, estando presente numa progressão gradual e contínua desde o $1^{\circ}$ ano até o $9^{\circ}$ ano, instrumentando os alunos para a investigação científica. $\mathrm{O}$ mesmo é proposto para os assuntos relacionados ao corpo humano, que devem fornecer bases científicas para os estudantes cuidarem da saúde individual, coletiva e ambiental, mas apresenta deficiências que, em algumas situações, fazem retroceder o currículo de Ciências.

Embora traga uma visão atual do ensino de Ciências da natureza para o nível fundamental, o documento apresenta um foco exclusivo na perspectiva de "letramento científico", não dando o devido destaque às abordagens das múltiplas interrelações entre ciência, tecnologia, sociedade e ambiente, prevalecendo um caráter mais de ênfase à aquisição da linguagem, conceitos e processos das Ciências. Isto é reforçado com a programação dos Objetos de Conhecimento e Objetivos de Aprendizagem ao longo dos nove anos do ensino fundamental, cuja tônica está na aquisição (de modo significativo, compreensivo, investigativo) de conceitos, fatos, características, leis, teorias.

Há necessidade de estimular situações interdisciplinares, de compreensão dos fenômenos (socio)ambientais em suas múltiplas dimensões e determinações e de atuação de maneira crítica, criativa, coletiva e transformadora do mundo vivencial das crianças e jovens. Há necessidade de rever as unidades temáticas, além de integrar seus respectivos objetivos num 


\section{HORIZONTES - REVISTA DE EDUCACATO}

E-ISSN: $2318-1540$

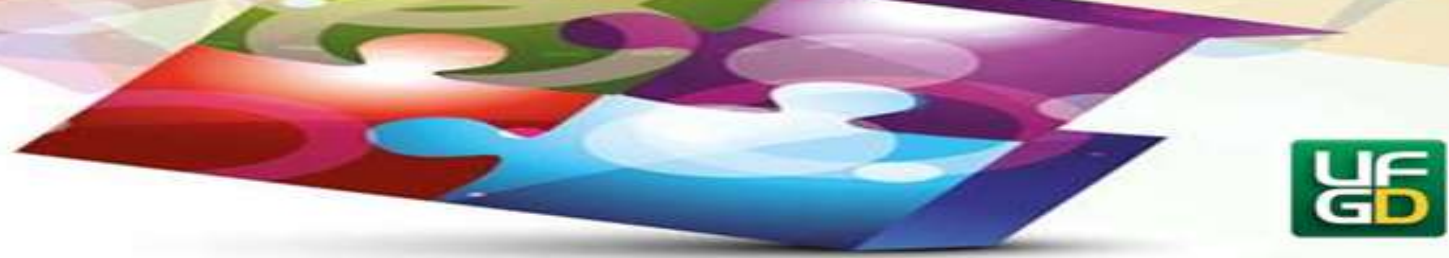

mesmo ano escolar e progressivamente ao longo dos anos e reposicioná-los no sentido de tornálos mais adequados às faixas etárias.

\section{PROCEDIMENTOS METODOLÓGICOS}

Em termos metodológicos, esse estudo caracteriza-se como uma pesquisa qualitativa e utiliza a combinação das pesquisas bibliográfica e documental. O levantamento bibliográfico auxilia no entendimento das contribuições já realizadas sobre a temática. Para Lakatos e Marconi (2003, p. 183), “[...] a pesquisa bibliográfica propicia o exame de um tema sob novo enfoque ou abordagem, chegando a conclusões inovadoras", possibilitando um novo olhar e uma nova perspectiva sobre a temática levantada.

No âmbito da pesquisa documental, confrontamos dois documentos: a BNCC (versão final) e o Referencial Curricular do Estado do Acre. Segundo Lüdke e André (1986, p. 39) os documentos constituem uma fonte rica e estável de pesquisa e, além disso, "servem de base a diferentes estudos, o que dá mais estabilidade aos resultados obtidos".

Assim, além de apresentar pontos que destacam o ensino de Ciências na BNCC (BRASIL, 2017) e na atual Proposta Curricular de Ciências do estado do Acre (2009, 2010), também fizemos interlocuções bibliográficas com autores que apresentam as questões históricas da BNCC e discutem a importância de se vislumbrar a educação para cidadania inclusiva (MACEDO, 2015; CURY, REIS, ZANARDI, 2018; LOPES, 2018).

\section{A BNCC E AS ORIENTAÇÕES CURRICULARES DE CIÊNCIAS NATURAIS DO ESTADO DO ACRE}

No ano de 2004, o Estado do Acre elaborou seu primeiro Referencial Curricular para a Educação Básica. A proposta pedagógica teve como referência as estruturas jurídicas presentes no Currículo oficial brasileiro, os PCNs, e alguns livros didáticos que eram usados pelos professores de Ciências da rede estadual de ensino (ACRE, 2004).

Em 2009, a Orientação Curricular utilizada na rede estadual do Acre, passou por um processo de reelaboração, sendo adotada pelas escolas públicas em 2010 com a finalidade de 


\section{HORIZONTES - REVISTA DE EDUCACATO}

e-ISSN: 2318-1540

apoiar as equipes escolares no processo de concretização do currículo que assegurasse a melhor aprendizagem possível para todos os alunos. O Referencial Curricular passou a ser descrito no documento como Série de Cadernos de Orientação Curricular- Orientações Curriculares para o Ensino Fundamental. O destinado ao ensino de Ciências foi denominado de Caderno 1 Ciências Naturais, baseado no antigo documento, nos PCNs e nos Parâmetros em Ação (ACRE, 2010).

O enfoque desta proposta centrava-se no desenvolvimento das capacidades humanas possibilitando aos alunos a utilização efetiva dos saberes aprendidos no seu cotidiano. Os conteúdos foram organizados em procedimentais, conceituais e atitudinais, objetivando desenvolver capacidade/ competência e habilidade/procedimentos.

Em 2017, a partir da aprovação da BNCC, os currículos dos sistemas e redes de ensino das unidades federativas, como também as propostas pedagógicas de todas as escolas públicas e privadas da Educação Básica passaram a ser norteados por esse documento. No estado do Acre, a Secretaria de Estado de Educação (SEE/AC) compôs uma equipe técnica de redatores, formada por assessores pedagógicos das redes estadual e municipal de Ensino, assim como profissionais de outras instituições, para reorganizar o seu documento curricular para o Ensino Fundamental.

A equipe de implementação da BNCC e de reelaboração do Currículo Único de Referência para o Estado do Acre, contou com técnicos de todas as áreas do conhecimento, bem como, assessores pedagógicos, leitores críticos, gestores e convidados. A proposta no Estado foi a construção, em regime de colaboração entre estado e municípios, de um Referencial Curricular Único, cujo objetivo é estabelecer direitos de aprendizagens a todos os estudantes do Estado em uma perspectiva de equidade, ou seja, de garantir as condições necessárias para que essas aprendizagens se efetivem.

O processo de reelaboração dessa proposta, iniciou em 2018, com consulta pública e aprovação no Conselho Estadual de Educação. A consulta pública visou a melhoria na qualidade dos conteúdos e nos textos em geral; Resolução dos pontos de atenção já identificados pelos redatores; Alinhamento de expectativas da rede e da equipe do currículo; Pensar coletivamente como é a escola e o que queremos garantir aos alunos; Aprimorar o currículo, cuidando para que as características culturais, socioambientais e econômicas do estado estejam contempladas; Pioneirismo em consultar as redes municipal, estadual e privada; Valorização 


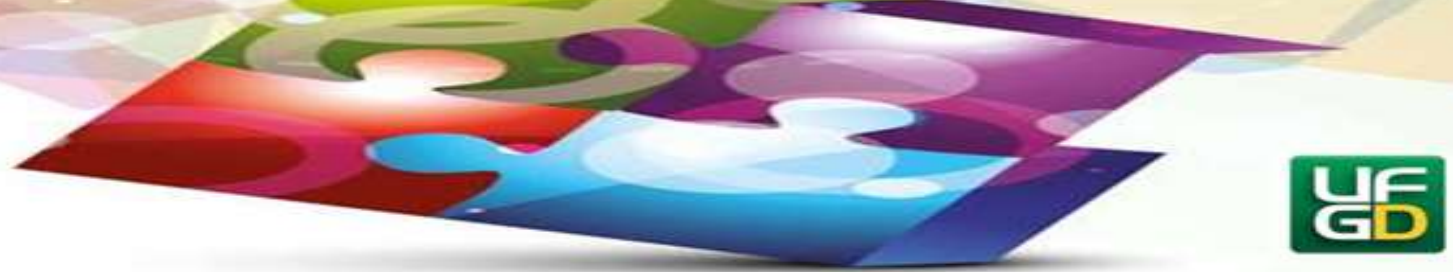

do professor e engajamento de quem atua na escola no dia a dia; provocar mudanças de rota para que os passos se alinhem com a Educação que esperamos para o Estado do Acre; Garantir a socialização de conhecimentos e a troca de experiências entre as redes estadual e municipais visando à melhoria do processo de revisão curricular

Para tanto, foram realizados dois tipos de consulta: a leitura crítica realizada entre os meses de agosto a novembro de 2018, direcionada aos especialistas, representantes das etapas, áreas, componentes ou modalidades. E a consulta pública, realizada em Rio Branco, capital do estado, nos meses de outubro e novembro, com a realização de estudos nas escolas e realização de evento presencial para discussão e sistematização das contribuições com o intuito de ouvir os municípios, professores, coordenadores pedagógicos e de ensino, gestores, pais, e comunidade escolar em geral. Nos demais municípios a consulta foi realizada em setembro e outubro, viabilizada pelas Comissões Municipais de Implementação da BNCC.

Em 2019 o processo de reelaboração do currículo do Acre seguindo as instruções do Conselho Estadual de Educação, deu destaque a formação dos professores, esse processo seguiu as seguintes etapas de trabalho:

a) Estudos dos textos introdutórios da BNCC, observando concepções e princípios fundantes; estudo da parte introdutória das Orientações Curriculares do Acre, observando divergências e conflitos; comparação da estrutura da BNCC e das Orientações Curriculares, verificando quais as alterações necessárias;

b) Estudo dos conceitos: competências, capacidades, habilidades e conteúdos, escolha metodológica, análise das competências gerais e da área, (re)elaboração do currículo, comparando as habilidades da BNCC e os conteúdos e capacidades;

c) Consulta pública da versão preliminar feita em 3 partes: consulta pública online, leitura crítica e Seminário Estadual; Consolidação da versão 1 sistematização e inclusão de considerações pertinentes acerca das habilidades e conteúdos.

d) Após as contribuições recebidas da consulta pública e das discussões realizadas nas escolas serem sistematizadas e integradas ao documento, este passou pela análise do Conselho Estadual de Educação do Acre, para emissão de parecer normativo. 


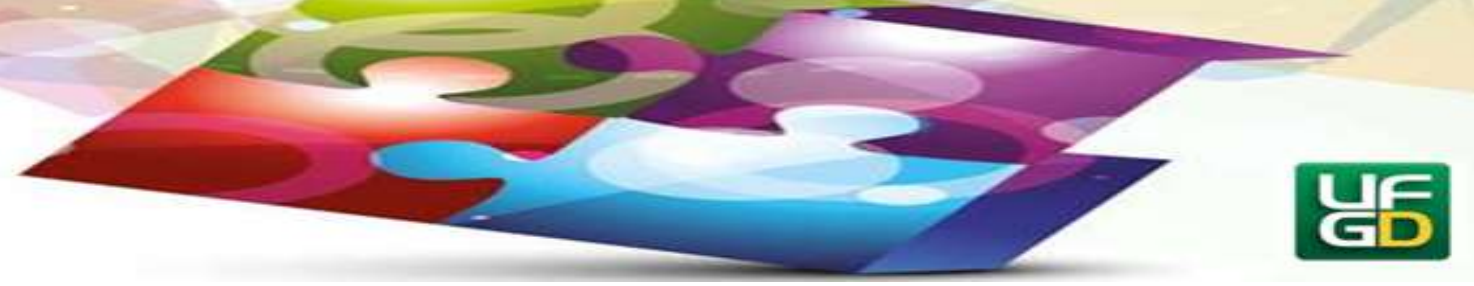

Considerando a finalização do Referencial em 2019, os sistemas de ensino passaram a orientar as escolas para a elaboração ou reelaboração das propostas curriculares e Projetos Políticos Pedagógicos. Nesse período, as redes promoveram formação continuada aos professores para efetivação dos currículos em 2020.

O Referencial Curricular do Acre contempla o conjunto de aprendizagens essenciais que os alunos devem desenvolver, ao longo das etapas e modalidades da Educação Básica, previstos na BNCC, acrescidos de conteúdos complementares, e integrados àqueles da BNCC, respeitando características regionais e locais da sociedade acreana.

O documento apresenta um texto introdutório sobre o Currículo de Referência Único no Acre, destaca o papel da escola e a formação integral dos estudantes, professores e estudantes: protagonistas do ensino e da aprendizagem; Os conceitos: direitos e objetivos de aprendizagem, capacidades, conteúdos, propostas de atividade e formas de avaliação. As políticas públicas para Educação de Jovens e Adultos, Educação Especial, Educação Rural, Educação Escolar Indígena, o lugar da cultura afro-brasileira, africana e indígena na educação escolar e os temas transversais e integradores.

A estrutura do novo currículo permaneceu a mesma já usada nas Orientações Curriculares no Estado desde 2009, com destaque para os objetivos, conteúdo, propostas de atividades e formas de avaliação. A principal tarefa da reelaboração foi incluir as habilidades da BNCC, mas sem mudar as concepções do Currículo do Acre.

Cabe destacar que a Resolução CEE/AC n ${ }^{\circ}$ 264/2018 artigo $8^{\circ}$, permite a adoção de um currículo único para todo o Estado através do Regime de Colaboração, oficializado a partir do Termo de Adesão, conforme indica a citada Resolução em seu Artigo $9^{\circ}$ inciso V. De acordo com o artigo $8^{\circ}$ da resolução $\mathrm{n}^{\mathrm{o}} 2$ (2017, p. 6), os currículos coerentes com a proposta pedagógica da instituição ou rede de ensino devem adequar as proposições da BNCC à sua realidade, considerando, para tanto, o contexto e as características dos estudantes, devendo:

I. Contextualizar os conteúdos curriculares, identificando estratégias para apresenta-los, exemplifica-los, conectá-los e torná-los significativos com base na realidade do lugar e do tempo nos quais as aprendizagens se desenvolvem e são constituídas; 
II. II. Decidir sobre formas de organização dos componentes curriculares disciplinar, interdisciplinar, transdisciplinar ou pluridisciplinar- e fortalecer a competência pedagógica das equipes escolares, de modo que se adotem estratégias mais dinâmicas, interativas e colaborativas em relação à gestão do ensino e da aprendizagem; [...]

III. III Selecionar e aplicar metodologias e estratégias didático pedagógicas diversificadas [...]

IV. IV. Conceber e pôr em prática situações e procedimentos para motivar e engajar os estudantes nas aprendizagens; [...] $\S 1^{\circ}$ Os currículos devem incluir a abordagem, de forma transversal e integradora, de temas exigidos por legislação e normas específicas, e temas contemporâneos relevantes para o desenvolvimento da cidadania, que afetam a vida humana em escala local, regional e global [...] (BRASIL, 2017, p. 6).

Observa-se que a BNCC traz uma preocupação com o ensino de forma integral, de modo que ofereça aos seus educandos um conhecimento sólido e globalizado. Assim, é oferecida a oportunidade aos sistemas escolares de adaptarem parte de seus currículos à realidade social e cultural da comunidade escolar. A proposta é que cada escola acrescente um diálogo com a BNCC e que a parte diversificada do currículo seja formulada de acordo com as especificidades do contexto onde está situada, tendo como foco o aperfeiçoamento do processo de aprendizagem.

No tocante as Orientações Curriculares de Ciências, a equipe de redatores da SEE/AC, desse componente, realizou um estudo da BNCC para a disciplina de Ciências do Ensino Fundamental, comparou com a Orientação Curricular estadual vigente (ACRE, 2009), e avaliou que, de modo geral, as competências específicas para o componente Ciências, previstas na BNCC, já estão contempladas na Orientação Curricular da SEE e, portanto, não realizaram grandes modificações na atual estrutura do documento, mas algumas inserções de abordagens de conteúdos propostos pela BNCC, que não estavam contemplados (SEE/AC).

Um dos aspectos positivos do documento é que este dá destaque a grande biodiversidade do estado, caracterizada por diferentes paisagens naturais, inseridas no ambiente da floresta tropical amazônica (ACRE, 2010), o que possibilita que os alunos construam um pensamento crítico sobre questões locais e globais e desenvolvam habilidades com base em procedimentos investigativos, reconhecendo a evolução histórica da Ciência. 


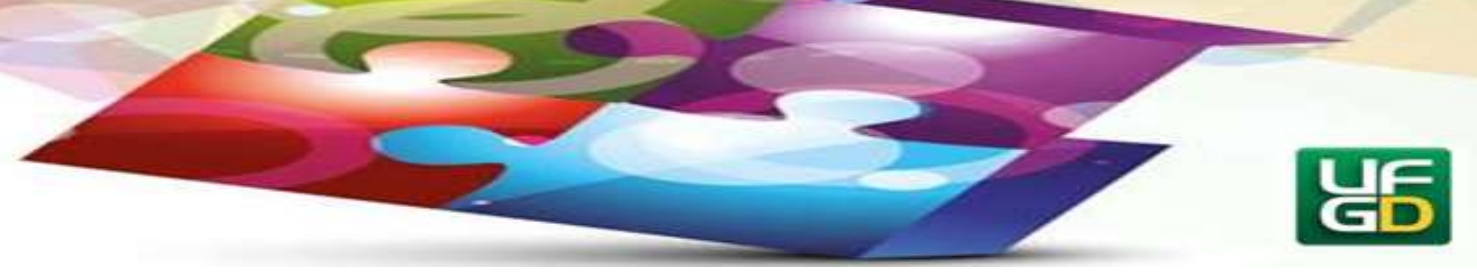

Nesse contexto, ao abordar conteúdos relacionados aos diferentes grupos de seres vivos, por exemplo, é proposto a caracterização de espécies de animais e plantas típicas das nossas florestas, que representam a rica biodiversidade do território acreano, a discussão sobre ações humanas que ameaçam esse patrimônio natural e a importância de sua conservação. Da mesma forma, no estudo sobre doenças veiculadas pela água e pelo solo, por exemplo, orienta-se a abordagem das doenças típicas da nossa região que estão relacionadas, dentre outros fatores, às condições climáticas da região, situação da atual estrutura de saneamento básico do Estado do Acre e outros aspectos socioeconômicos e culturais envolvidos (RCU, 2018)

O documento ressalta, ainda, a necessidade de cada instituição escolar mesclar a parte comum à parte diversificada, em seu currículo próprio, que será elaborado coletivamente por toda a comunidade escolar. Assim como os demais estados brasileiros, os acreanos terão que seguir a BNCC, as Orientações Curriculares para o Ensino de Ciências que, antes, tinham nos PCN uma diretriz, precisam, também, se adaptar às novas normas advindas com a BNCC. (BNCC, 2017).

Devido ao isolamento geográfico, os professores acreanos enfrentam alguns desafios por conta da dinamização e acesso em massa dos meios tecnológicos e da informatização que nos chegam a todo o momento por meio do rádio, televisão, internet e redes sociais. Toda essa globalização da tecnologia exige que o Ensino de Ciências se adapte a essas novas experiências por que passam nossos jovens. Tal situação exige que estes estejam continuamente em atualização e busquem novas metodologias para que possam acompanhar as transformações científico-tecnológicas da contemporaneidade e as novas exigências advindas com a BNCC.

O documento também traz orientações aos docentes para que os conteúdos ministrados em sala de aula do ensino de Ciências, sejam tratados na escola de uma forma contextualizada, estabelecendo relações interdisciplinares entre eles, pois contribuem para que os alunos sejam capazes de desenvolver um olhar crítico frente às inovações tecnológicas e científicas nos contextos em que se constituem.

Observa-se a preocupação dessa proposta em trabalhar a disciplina de Ciências de forma integrada com as demais áreas do conhecimento, instituindo a vida cidadã como processos articulados de construção, amadurecimento, e apropriação de valores para a formação integral e interdisciplinar dos alunos. Assim, tendo os alunos um conhecimento global, estarão aptos para caminhar em busca de sua autonomia política, econômica e social. 


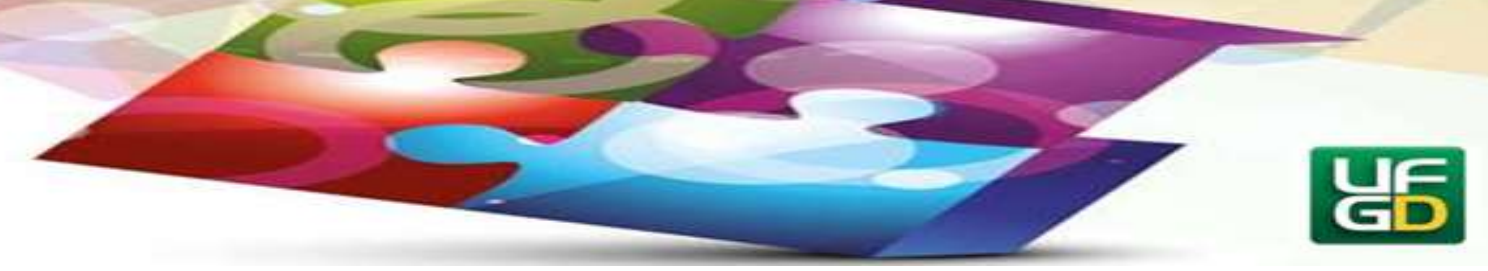

Como desafio pedagógico, o documento propõe que o ensino de Ciências seja abordado com foco em uma metodologia participativa e problematizada, através da qual os conhecimentos prévios dos alunos sejam o ponto de partida para a ação do professor dentro e fora da sala de aula.

Dessa forma, de acordo com o documento, cumpre-se a tarefa essencial da educação: favorecer a todos os alunos o contato harmonioso com o conhecimento das diferentes áreas. Esse conhecimento integrado e contextualizado do Ensino de Ciências com as demais áreas do conhecimento pode ser realizado de forma dinâmica, despertando o interesse dos educandos pelo processo de ensino-aprendizagem através de abordagens interdisciplinares no processo de contextualização dos conceitos científicos com a realidade do aluno e com seu convívio social, bem como com as demais disciplinas curriculares.

Tanto na BNCC quanto nas Orientações Curriculares de Ciências Naturais, destaca-se a preocupação com o fortalecimento da Educação Básica, dando ênfase à questão da relação educação/cidadania. A escola deve englobar questões sociais e problemas cotidianos dos alunos, que possam alcançar os objetivos e finalidades educacionais. A contextualização do conhecimento em busca da formação integral e cidadã do educando tornou-se um dos principais meios de galgar as finalidades do Ensino Fundamental.

Em ambos os documentos observa-se o agrupamento dos conteúdos disciplinares semelhantes, tais como: os diferentes grupos de seres vivos, doenças veiculadas pela água e pelo solo, o funcionamento do corpo humano, dentre outros. Percebe-se apenas a mudança de nomenclaturas, e as orientações de que estes devem ser trabalhados de forma contextualizada e com metodologias diversificadas de ensino, ou seja, o destaque para a não fragmentação do conhecimento está presente em vários momentos nos dois documentos.

A BNCC nos traz novamente, dentre outros aspectos, os objetivos da aprendizagem, que na proposta acreana apresentam-se mais como uma orientação sobre o que ensinar, estando expostos dentro dos blocos de conhecimento, diferentemente da Base, que os apresenta em cada ano do ensino, mostra de forma incisiva o que ensinar em cada ano, ou seja, mostra-se mais específica, determinando, com mais clareza, as habilidades que os educandos devem desenvolver em cada fase/ano da Educação Básica.

Embora as redes de ensino precisem ter a BNCC como referência para seus trabalhos, elas devem ter sua autonomia preservada. Isso fica claro no próprio documento, quando se 


\section{HORIZONTES - REVISTA DE EDUCACATO}

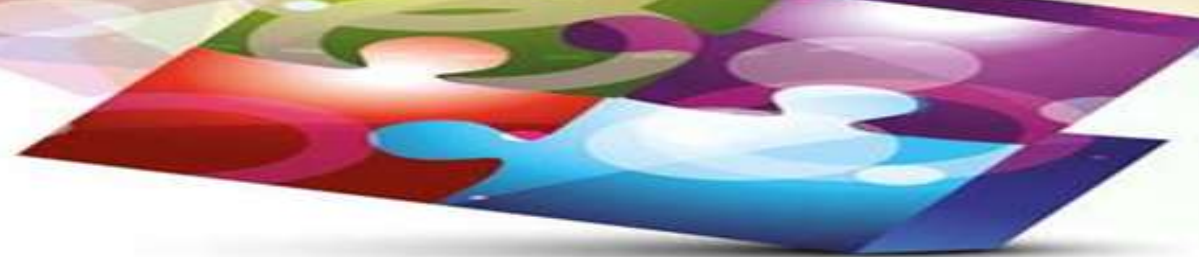

refere à abordagem de temas contemporâneos que afetam a vida global e local. Todas essas orientações são destacadas no plano de ação para a aprendizagem: [...] BNCC e currículos têm papéis complementares para assegurar as aprendizagens essenciais definidas para cada etapa da Educação Básica, uma vez que tais aprendizagens só se materializam mediante o conjunto de decisões que caracterizam o currículo em ação [...]. Essas decisões que resultam de um processo de envolvimento e participação das famílias e da comunidade, referem-se, entre outras ações, a: contextualizar os conteúdos dos componentes curriculares, identificando estratégias para apresentá-los, representá-los, exemplifica-los, conectá-los e torná-los significativos, com base na realidade do lugar e do tempo nos quais as aprendizagens estão situadas; decidir sobre formas de organização interdisciplinar dos componentes curriculares e fortalecer a competência pedagógica das equipes escolares para adotar estratégias mais dinâmicas, interativas e colaborativas em relação á gestão do ensino e da aprendizagem; [...] (BRASIL, 2017, p. 12).

O Referencial Curricular Único do Acre constitui um documento que orienta o planejamento de ensino dos professores, priorizando atividades capazes de propiciar aprendizagens significativas e dessa forma estabelecer estratégias para melhorar a qualidade do ensino e da aprendizagem. Com base neste Referencial, as escolas poderão a partir de 2020 elaborar o seu currículo adequando-o às especificidades e peculiaridades, de acordo com a etapa de ensino ofertada e/ou modalidade de ensino atendida, considerando também os aspectos regionais e locais. É importante destacar que a construção do Projeto Político Pedagógico das escolas e os planos de aula dos professores devem ser feitos de modo contextualizar as aprendizagens à realidade de cada cidade, de cada bairro, de cada escola e com o olhar de cada professor.

\section{CONSIDERAÇÕES FINAIS}

O Referencial Curricular do Acre foi (re)elaborado em 2018, com a finalidade de se alinhar a BNCC, mas incorpora na sua estrutura itens que se propõem a favorecer uma compreensão mais precisa do que é pretendido; e na definição de conteúdo acrescenta aqueles que aprofundam a identidade acreana, buscando, assim, promover o conhecimento de aspectos importantes para a cultura e a história do Estado, ou seja, busca aprimorar o currículo, cuidando 


\section{HORIZONTES - REVISTA DE EDUCACATO}

E-ISSN: 2318-1540

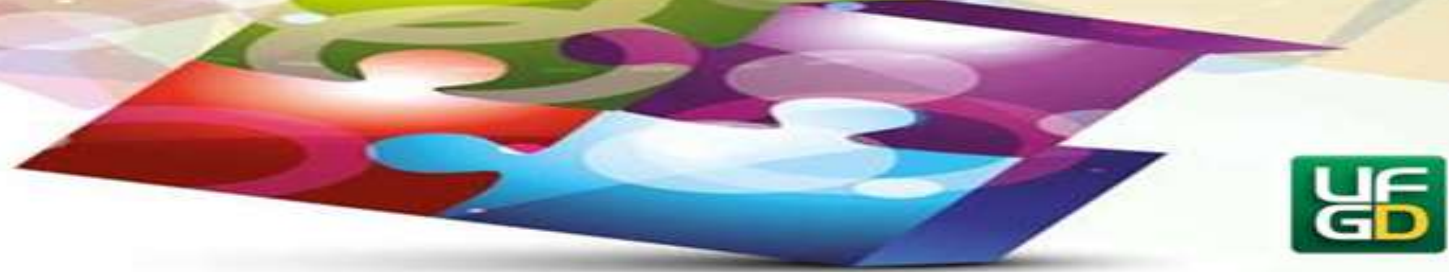

para que as características culturais, socioambientais e econômicas do estado estejam contempladas.

Mais do que um referencial norteador dos compromissos que devem ser assumidos pelos gestores públicos do estado e de municípios que o integram, significa a decisão política dos educadores acreanos sobre a escola democrática, com qualidade social e com perspectiva cidadã, que, compreendem, precisa ser garantida às crianças, adolescentes, jovens e adultos do Acre, como de todo o país.

Por isso, pensar na BNCC como ponto de partida para a (re)elaboração do Referencial Curricular do Acre é também pensar em uma decisão política que busca a manutenção da cidadania, tão fundamental à educação acreana. Na verdade, para Cury, Reis e Zanardi (2018, p. 48), a BNCC está vinculada à constituição de uma cidadania portadora de representatividade e participação, já que "a educação escolar é uma forma de viabilizar esta vida cidadã nos espaços de uma coesão nacional".

Nesse sentido, é essencial que as políticas públicas acreanas prossigam com seriedade e se afastem das decisões que podem levar ao prejuízo "das questões sociais, da formação crítica, da cidadania, do direito que se diz estar defendendo" (OLIVEIRA, 2018, p. 57). Logo, viabilizar um ensino de Ciências para a cidadania é também uma forma de manter práticas políticas responsáveis com os cidadãos acreanos.

\section{REFERÊNCIAS BIBLIOGRÁFICAS}

ACRE. Secretaria de Estado de Educação. Série Cadernos de orientação curricular:

Orientações Curriculares para o Ciclo Inicial do Ensino Fundamental, Volumes 1, 2, 3, 4 e 5, Rio Branco, AC. SEE, 2009.

ACRE. Secretaria de Estado de Educação. Série Cadernos de orientação curricular:

Orientações Curriculares para o Ensino Fundamental - Caderno 1 - Ciências Naturais, Rio Branco, AC. SEE, 2010.

BRASIL. Base Nacional Comum Curricular (BNCC). Educação é a Base. Brasília, MEC/CONSED/UNDIME, 2017.

BRASIL. Congresso Nacional. Constituição da República Federativa do Brasil. Brasília: Imprensa Oficial, 1988. Disponível em: <www.planalto.gov.br〉. Acesso em: 10 nov. 2019. 


\section{HORIZONTES - REVISTA DE EDUCACATO}

e-ISSN: $2318-1540$

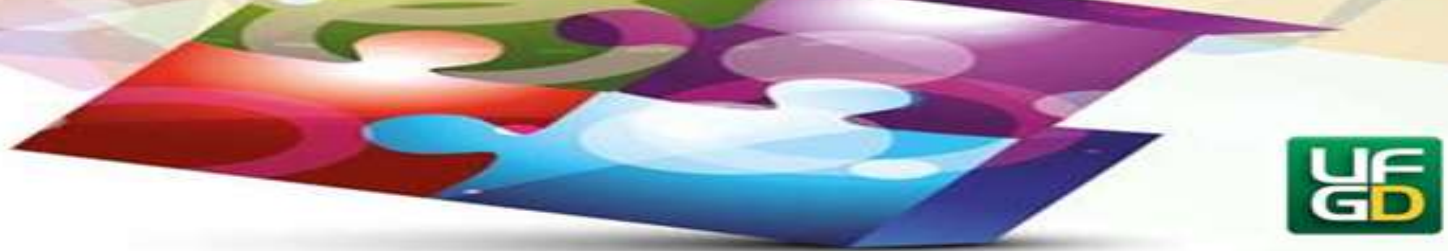

BRASIL. Lei das Diretrizes e Bases da Educação Nacional. Lei no 9394 de 1996. Brasília, 1996. Disponível em: <www.planalto.gov.br>. Acesso em: 10 nov. 2019.

BRASIL. Ministério da Educação e do Desporto. Secretaria de Educação Fundamental. Parâmetros Curriculares Nacionais: Ensino Fundamental. Brasília: MEC/SEF, 10 volumes, 1998.

BRASIL. Plano Nacional de Educação. Lei n 13.005 de 2014. Disponível em: $<$ http://pne.mec.gov.br/18-planos-subnacionais-de-educacao/543-plano-nacional-deeducacao-lei-n-13-005-2014>. Acesso em: 10 nov. 2019.

CURY, C.R.J.; REIS M.; ZANARDI, T.A.C. Base Nacional Comum Curricular: dilemas e perspectivas. São Paulo: Cortez, 2018.

CURY, C.R.J. Sistema nacional de educação: desafio para uma educação igualitária e federativa. Educ. Soc., v. 29, n. 105, p. 1187-1209, dec. 2008. Disponível em:

<http://www.scielo.br>. Acesso em: 10 nov. 2019.

LAKATOS, E. M.; MARCONI, M. A. Fundamentos de metodologia científica. 5. ed. São Paulo: Atlas, 2003.

LOPES, A.C. Apostando na produção contextual do Currículo. In: AGUIAR, M.A.S.; DOURADO, L.F. (Orgs.) A BNCC na contramão do PNE 2014-2024: avaliação e perspectivas. [Livro Eletrônico]. Recife: ANPAE, 2018. Disponível em:

<http://www.anpae.org.br/BibliotecaVirtual/4-Publicacoes/BNCC-VERSAO-FINAL.pdf>. Acesso em: 10 nov. 2019.

LÜDKE, M. e ANDRÉ, M.E.D.A. Pesquisa em educação: abordagens qualitativas. São Paulo: EPU, 1986.

OLIVEIRA, I.B. Políticas curriculares no contexto do golpe de 2016: debates atuais, embates e resistências. In: AGUIAR, M.A.S.; DOURADO, L.F. (Orgs.) A BNCC na contramão do PNE 2014-2024: avaliação e perspectivas. [Livro Eletrônico]. Recife: ANPAE, 2018. Disponível em: <http://www.anpae.org.br/BibliotecaVirtual/4-Publicacoes/BNCC-VERSAOFINAL.pdf $>$. Acesso em: 10 nov. 2019.

MACEDO, E. Base Nacional Comum para Currículos: direitos de aprendizagem e desenvolvimento para quem? Educ. Soc., Campinas, v. 36, nº . 133, p. 891-908, out.-dez., 2015. Disponível em: <http://www.scielo.br/pdf/es/v36n133/1678-4626-es-36-13300891.pdf $>$. Acesso em: 10 nov. 2019.

Enviado: $15 / 11 / 2019$

Aceito: 09/06/2020 